Table S1. Influenza $\mathrm{A} H 3$ and $\mathrm{H1}$ antigenic site maps

a. H3 Antigenic site map (A-E: 131 amino acid residues) shown as amino acid (AA) number of the HA1 protein [1-3]

\begin{tabular}{|c|c|}
\hline $\begin{array}{c}\text { Antigenic Site } \\
(\mathrm{n}=\text { =number of } \\
\text { residues in total })\end{array}$ & Residue Number(s) \\
\hline A (n=19) & $\begin{array}{c}122,124,126,130-133,135,137,138,140,142-146,150,152, \\
168\end{array}$ \\
\hline B (n=22) & $128,129,155-160,163-165,186-190,192-194,196-198$ \\
\hline C (n=27) & $\begin{array}{c}44-48,50,51,53,54,273,275,276,278-280,294,297,299, \\
300,304,305,307-312\end{array}$ \\
\hline D (n=41) & $\begin{array}{c}96,102,103,117,121,167,170-177,179,182,201,203,207- \\
209,212-219,226-230,238,240,242,244,246-248\end{array}$ \\
\hline E $(n=22)$ & $\begin{array}{c}57,59,62,63,67,75,78,80-83,86-88,91,92,94,109,260- \\
262,265\end{array}$ \\
\hline
\end{tabular}

b. H1 Antigenic site map (Sa, Sb, Ca1, Ca2, and Cb: 50 amino acid residues) shown as AA number of the HA1 protein $[2,4]$

\begin{tabular}{|c|c|}
\hline $\begin{array}{c}\text { Antigenic Site } \\
(\mathbf{n}=\text { number of } \\
\text { residues in total })\end{array}$ & Residue Number(s) \\
\hline Sa $(n=13)$ & $124,125,153-157,159-164$, \\
\hline Sb $(n=12)$ & $184-195$ \\
\hline Ca1 $(n=11)$ & $166-170,203,204,205,235-237$ \\
\hline Ca2 $(n=8)$ & $137-142,221,222$ \\
\hline$C b(n=6)$ & $70-75$ \\
\hline
\end{tabular}

\title{
References S1:
}

1 Skowronski DM, Janjua NZ, De Serres G, Winter AL, Dickinson JA, et al. (2012) A sentinel platform to evaluate influenza vaccine effectiveness and new variant circulation, Canada 2010-11 season. Clin Infect Dis 55: 332-342.

2 Skowronski DM, Janjua NZ, Sabaiduc S, De Serres G, Winter A-L, et al. (2014) Influenza A/subtype and $\mathrm{B} /$ lineage effectiveness estimates for the 2011-12 trivalent vaccine: cross-season and cross-lineage protection with unchanged vaccine. J Infect Dis. Doi:10.1093/infdis/jiu048

3 Bush RM, Bender CA, Subbarao K, Cox NJ, Fitch WM (1999) Predicting the evolution of human influenza A. Science 286: 1921-1925.

4 Brownlee GG, Fodor E (2001) The predicted antigenicity of the haemagglutinin of the 1918 Spanish influenza pandemic suggests an avian origin. Phil Trans R Soc Lond 356: 1871-1876. 